\title{
Computed tomography in staging for lung cancer
}

\author{
J.A. Verschakelen, J. Bogaert, W. De Wever
}

\begin{abstract}
Computed tomography in staging for lung cancer. J.A. Verschakelen, J. Bogaert, W. De Wever. C) ERS Journals Ltd 2002.

ABSTRACT: Computed tomography (CT) provides the most detailed imaging information, hence it is generally used as a routine imaging procedure in the tumour, node, metastasis (TNM)-staging of patients with lung cancer. However, despite the continuously ongoing process of improvement in CT scanning in which today's CT scanners combine fast acquisition, fast data reconstruction and high detail, the technique has important limitations.

CT can, in some cases, very accurately show tumour extent within, and predict spread beyond the lung. However, the question of whether the tumour has invaded the chest wall or the mediastinum and, if so, whether it is still potentially surgically curable often remains unanswered. In addition, the only sign for predicting lymph node involvement using CT is enlargement. Many studies have shown that this sign is not very reliable. CT is also, with success, being used to evaluate distant metastases although other techniques such as ultrasound and magnetic resonance imaging can have similar or higher accuracies.

Despite these well-known limitations, computed tomography will most likely stay the routine imaging procedure for determining resectability and for assessing intra- and extrathoracic spread of lung cancer. The improvement in technology will probably result a better T-staging. The role of computed tomography in nodal staging remains important. It offers the surgeon a road map of the lymph nodes and guides towards the nodes that need biopsy. Combining computed tomography with positron emission tomography, when it becomes more widely available, will add functional images to the detail of computed tomography and will not only improve nodal staging but will probably also allow a better evaluation of distant metastasis and reduce the number of unnecessary interventional procedures.

Eur Respir J 2002; 19: Suppl. 35, 40s-48s.
\end{abstract}

Dept of Radiology, University Hospitals, Leuven, Belgium.

\author{
Correspondence: J.A. Verschakelen \\ Dept of Radiology \\ University Hospitals \\ Herestraat 49 \\ 3000 Leuven \\ Belgium \\ Fax: 3216343765 \\ E-mail: johny.verschakelen@ \\ uz.kuleuven.ac.be
}

Keywords: Computed tomography
lung neoplasms staging

Received: August 102001

Accepted after revision August 202001
Since its introduction in the early seventies, computed tomography (CT) has been used to stage patients with lung cancer. Compared with the chest radiograph, CT offers important additional information not only about the localization, size and extent of the primary tumour but also about the locoregional and distal spread of this tumour. The major advantages of this technique are related to its axial format, its higher density resolution and its wider dynamic range. Continuous technical improvements and the development of more powerful and faster computers are responsible for the fact that today's CT examinations of the chest result in a large amount of detailed imaging information obtained in a very short time. Because of this evolution in technique, and also due to the development of new therapy strategies for lung cancer and the recent introduction of positron emission tomography (PET), the contribution of CT to the staging of patients with lung cancer is changing continuously.

This review will start with a paragraph on the technical aspects of CT. Then the potential role of CT in locoregional ( $\mathrm{T}$ and $\mathrm{N}$ ) and distal (M) staging will be discussed. The final paragraph will conclude and reflect on the future of $\mathrm{CT}$ in tumour, node, metastasis (TNM) staging.

\section{Technical aspects of computed tomography}

CT has developed rapidly since its introduction in about 1973. Although the basic parts of a CT system are unchanged (consisting of a gantry that contains the moving X-ray tube and detectors, a table supporting the patient, a computer, and a viewing console), multiple improvements have been responsible for the fact that today's examinations and resulting images are incomparable with those of the early days. Depending on the temporal relationship between the X-ray tube rotation and the table translation, and on the number of detector rows three types of CT systems can be distinguished: incremental or conventional CT, spiral or helical CT and multidetector or multislice CT.

During incremental or conventional CT the X-ray tube rotates around the patient while the table is immobile. The patient suspends respiration for a few seconds needed to complete one scan. The table moves 
and the procedure is repeated. Approximately 50 contiguous sections $5-10 \mathrm{~mm}$ thick are usually required to image the entire thorax, a process that takes $\sim 5-10 \mathrm{~min}$. As each CT image is acquired, it is displayed on the monitor and then transferred to hardcopy film. Thoracic CT's are usually imaged on gray scales optimized to visualize both the mediastinum (mediastinal windows) and the lung (lung windows). Intravenous contrast can be administered during the examination, as contrast enhancement may be helpful in differentiation of vessels from mediastinal structures [1-3].

In spiral CT, which was introduced in 1989, X-ray source rotation and patient table translation are performed simultaneously [4, 5]. Consequently, raw data acquisition time is greatly reduced and can be performed during a consistent respiratory level (one breath hold). Fast computers are necessary to calculate the transverse images from these raw data. An important feature of spiral CT is that retrospective reconstruction may be performed; that is, any transverse slice with a slice thickness chosen at data acquisition can be specified for reconstruction afterwards. In this way overlapping reconstructions can be made allowing substantially better longitudinal resolution than incremental $\mathrm{CT}$. Because the data set is continuous, correct multiplanar and threedimensional (3D) corrections also become possible. Spiral CT is more complex than conventional CT. There are more parameters that have to be chosen before the examination can be started and requirements for data storage are increased. In addition because more information can be retrieved from the raw data set, interpretation time can also increase.

Multidetector or multislice CT was only recently introduced. It uses multiple detector rows as opposed to one detector row in spiral CT. Detectors have different sizes and can be combined. For example, the Siemens Somatom Plus 4 Volume Zoom (Siemens, Erlangen, Germany) uses four detectors at a time and can use $1-\mathrm{mm}$ detectors $(4 \times 1), 2.5 \mathrm{~mm}$ detectors $(4 \times 2.5)$ or $5 \mathrm{~mm}$ detectors $(4 \times 5)$. Depending on the parameter selection, images can be reconstructed at slice thickness ranging from $1-10 \mathrm{~mm}$. Selection of the slice collimation can be done after the data are acquired in contrast to single detector (spiral) CT where the slice collimation is chosen prior to data acquisition and is fixed. In this way multidetector CT (MDCT) combines faster acquisition and high spatial resolution [6-8].

High resolution CT (HRCT) is not a CT system but an acquisition technique and can be performed with either conventional, spiral or multidetector CT. Its main characteristic is the high spatial resolution of the images that are obtained by using thin $(1-1.5 \mathrm{~mm})$ slices in combination with special high resolution computer algorithms [9, 10]. In conventional and spiral CT slice collimation has to be selected prior to the examination. Hence, it is impossible to scan the entire thorax in high-resolution mode with these systems. That is why HRCT is predominantly used to study diffuse lung diseases and only rarely to study detailed characteristics of focal lung lesions. Because in MDCT slice thickness can be chosen after data acquisition, combining thin high-resolution slices and thick slices in one examination is now possible.

The particular advantages of CT in imaging the thorax are its cross-sectional image format, superior density resolution, and wide dynamic range. The cross-sectional image format clearly separates structures that are superimposed on conventional radiographs. The high degree of density resolution reveals the individual structures of the mediastinum and chest wall within their surrounding fat. The wide dynamic range encompasses the whole spectrum of tissue density in the thorax. No other radiographical technique can capture lung, soft tissue and bone detail simultaneously with a single exposure.

The development of spiral CT and MDCT has been part of the continuously ongoing process of improvement in CT scanning. Today's CT scanners combine fast scan acquisition, fast data reconstruction and very high spatial resolution. CT scanning has, however become more complex. More scanning parameters need to be established while larger volume data sets become available. Dealing with these large volume data sets is another challenge. While in the early years 40-50 scan slices were available for interpretation, MDCT can easily produce 200-500 scan slices in a much shorter time. Recent system requirements for such processes as $3 \mathrm{D}$ imaging dealt with 80-150 slices while today's workstations need to be able to process up to $500-800$ scan slices. Improvement in technology has also resulted in new applications such as volume rendering, virtual bronchoscopy and real-time imaging. These techniques will be discussed further in this issue in the paper by Schaefer-Prokop and Prokop [11]. Other challenges with these large data sets are data storage and image transfer. They are also a challenge for the radiologist who needs to switch from film interpretation to interpretation on computer reading stations in order to cope with the enormous amount of information available.

\section{Locoregional staging}

\section{The T-factor}

Currently CT continues to play a major role in the preoperative staging of nonsmall cell lung cancer, for separating those patients with localized disease who are likely to benefit from surgical resection from those who have inoperable disease. PRIMACK et al. [12] found that in a series of 275 patients, $24 \%$ of patients with CT findings suggesting bronchogenic carcinoma had unequivocal evidence that the tumour was unresectable. However, very often CT scanning disagrees with the tumour stage found at surgery [13-15). Even though CT can provide important information as to whether or not the tumour has invaded the central vessels, the bronchial tree or the chest wall or has crossed the fissure, in many cases the surgeon still makes a final decision based on the findings at bronchoscopy and thoracotomy [16, 17].

Certain CT findings have been demonstrated as being diagnostic of unresectable disease such as gross 
invasion of the mediastinum with encasement, and distortion of the vascular structures of the mediastinum, or when lysis of a vertebral body adjacent to the tumour is seen. Contact between the tumour and the adjacent mediastinal structures does not necessarily indicate invasion, though the greater the degree of contact the more likely it is that the mediastinum has been invaded (fig. 1a). Herman et al. [18] demonstrated that the positive predictive value for vascular invasion changed from $56 \%$, when using a criterion of contact $>90^{\circ}$, to $100 \%$ when $>180^{\circ}$ was used. GLAzER et al. [19] suggested that a tumour is likely to be technically resectable if $\geqslant 1$ of the following features are present: 1) $<3 \mathrm{~cm}$ of contact between the tumour and the mediastinum; 2) $<90^{\circ}$ of circumferential contact with the aorta; and 3) a visible mediastinal fat plane between the tumour and the mediastinal structure. This does, however, not mean that a tumour with a contact of $>3 \mathrm{~cm}$ or with an absent mediastinal fat plane is always irresectable. In the series of GLAzER et al. [19], in almost $50 \%$ of the tumours that proved resectable a contact of $>3 \mathrm{~cm}$ was present $[19,20]$. Conversely, in a study of 108 patients, IzBICKI et al.
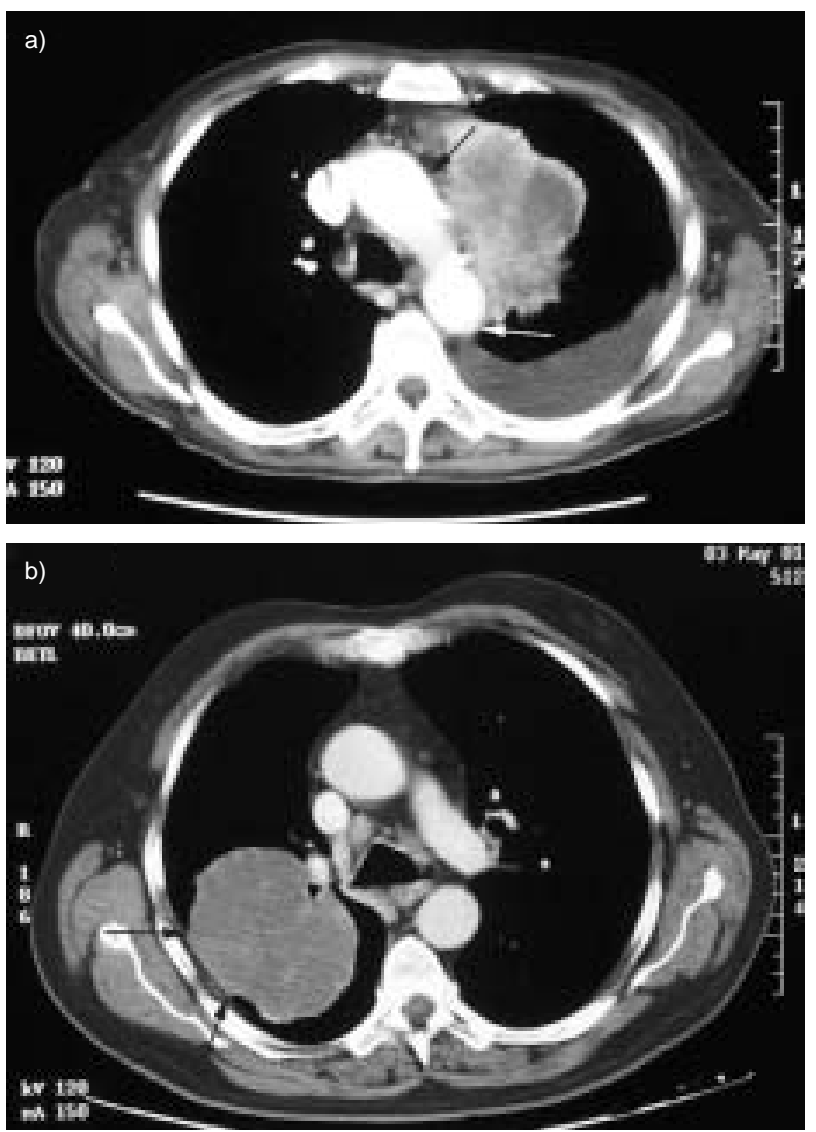

Fig. 1.-a) Large necrotic mass in the left upper lobe. There is a large amount of contact between the tumour and aortic arch (arrows) and a very irregular delineation of the vessel making tumoral invasion very likely. b) Large mass in the right upper lobe. Despite the large amount of contact between the tumour and the chest wall (arrows), there is no pleural thickening, the angles between the tumour and the chest wall are sharp and the extrapleural fat is preserved suggesting that the mass is not invading the pleura.
[21] reported one false-positive case for aortic invasion and multiple false-negative cases for invasion of an atrium, pulmonary artery, superior vena cava or mediastinal bronchus. It can be concluded that the accuracy of CT to distinguish between resectable (T3) and unresectable (T4) cancers is low.

The presence of chest wall invasion alone does not preclude surgical resection, though it does adversely affect the patient's prognosis $[22,23]$. An important role of CT is to help the surgeon to know preoperatively whether chest wall invasion is very likely and the depth of this invasion. However, the accuracy of CT in those cases where the tumour is adjacent to the chest wall without any bone destruction is low with sensitivity ranging from $38-87 \%$ and specificity from $40-90 \%$ [24-29]. Features such as a large contact $(>3 \mathrm{~m})$ between the mass and the pleura, an obtuse angle between the tumour and the chest wall, an associated pleural thickening, and the presence of pleural tags, usually considered as signs of chest wall invasion, also occur with benign lesions (fig. 1b). Obliteration of the extrapleural fat together with a great degree of pleural contact and extensive pleural thickening have been described as signs that make pleural invasion very likely [30]. Also the presence of an extrapleural mass is very suggestive of chest wall invasion by tumour. However, also this sign can be misleading, since infiltration of the extrapleural fat and the presence of an extrapleural mass can be due to inflammation and fibrosis rather than tumour [24]. A clear extrapleural fat plane adjacent to the mass, on the other hand, is not at all definitive in excluding chest wall invasion [31]. In summary, these studies suggest that the most reliable criterion for diagnosing chest wall invasion with routine CT is definite bone destruction, with or without tumour mass extending into the chest wall. Many attempts have been made to improve the accuracy of CT to predict tumoural invasion into the chest wall. It has been shown that the presence of respiratory shift which is defined as a change in the relative location between the peripheral tumour and the chest wall with deep inspiration and expiration at CT is a reliable indicator of the lack of parietal invasion of tumour located in the middle and lower lobes [32-34]. However absence of this shift does not necessary indicate tumour invasion since it can be caused by benign inflammatory or fibrous adhesions. The use of thin sectional (HRCT) can also improve the diagnostic accuracy of chest wall infiltration [35]. Two-dimensional (2D) and 3D reformations obtained with spiral CT have also been used successfully to study the relationship between lung tumours and pleural surface $[36,37]$. In a study where $2 \mathrm{D}$ and 3D images obtained with spiral CT in 42 patients with peripheral bronchogenic carcinoma were reviewed, KurIYAma et al. [37] found that 3D reconstruction imaging was superior to $2 \mathrm{D} \mathrm{CT}$ in the assessment of pleural invasion. 3D reconstructions allowed them to correctly predict visceral pleural involvement in $92 \%$ of patients compared to only $17 \%$ of patients with the use of 2D CT imaging. In cases where tumour invasion in the chest wall is obvious, 2D sagittal or frontal reformatted images can be helpful in ascertaining the extent of the mass. It has been shown that, 
considering surgical planning of endobronchial tumours, multiplanar reconstructions often provide a better understanding of tumoural implantation compared with cross-sectional images and endoscopic examination [38]. The continuous technical improvement has allowed the development of other post-processing techniques. Virtual endoscopy is a technique in which data acquired by spiral CT are reformulated to provide an internal rendering of the tracheobronchial walls and lumen. Among the potential advantages of this technique compared with real endoscopy are: 1) the interactive control of all virtual camera parameters including the field of view; 2) the ability to pass through the wall and look at the neighbouring anatomy; and 3) the ability to localize the $3 \mathrm{D}$ position of the virtual endoscope [39, 40].

Virtual endoscopy does, of course, not have the potential to replace real endoscopy because it cannot analyse mucosal abnormalities or obtain histological samples. Sophisticated workstations offering computeraided diagnosis and volumetric quantification of lung tumours are being developed in order to help the radiologist in the detection and follow-up of lung tumours.

Although most of these post-processing techniques are still in an evaluation phase and have not reached the daily clinical practice yet, their rapid development should be underlined and it can be expected that their impact on CT lung cancer staging will increase. Recently developed CT-positron emission tomography (PET) scanners, which combine computed tomography and ${ }^{18}$ F-fluoro-2-deoxyglucose (FDG)-PET in one system, add functional information to the morphological information obtained with CT. It is very likely that simulation, treatment planning, and guidance of therapeutic or diagnostic interventions using 3D, multiplanar reformatting (MPR), virtual endoscopy and multimodality imaging technologies will be routinely applied in the near future [41, 42].

Clearly, this ongoing maturation of CT into a fast and efficient diagnostic tool will further influence the potential role of magnetic resonance imaging (MRI) in staging patients with lung cancer. The diagnostic power of MRI is limited by its inability to produce images of the lung that are high in spatial resolution, and by the fact that it requires greater physician supervision than CT scanning to direct imaging and to maintain examination quality. Nevertheless, this technique can be a useful complement to CT scanning [43]. It has proved superior to CT for identifying involvement of major mediastinal blood vessels and the tracheal carina [17]. Invasion or encasement of the mediastinal vessels and the pulmonary arteries are usually readily identified. In some series MRI was better than CT in demonstrating chest wall and diaphragmatic invasion [44, 45]. Sagittal and coronal MRI often display the anatomical relationship in the lung apex more clearly than routine axial images, and thus are better suited to depicting apical tumour extent. MRI is currently still considered the image modality of choice for studying superior sulcus tumours and their extension to the chest wall [46-49].

Although CT suffers from the presence of beamhardening artifacts related to the adjacent lung structures as well as from a poorer contrast resolution, a significant problem for the study of the brachial plexus, it can be expected that this technique will gain importance in the future. In a study where tumour extension into the chest wall was examined with both spiral CT and MRI, the two techniques showed comparable sensitivity but spiral CT had a higher specificity [50].

CT can also be helpful to depict and study associated findings or complications in the chest. A lung tumour may be complicated by an obstruction of a major bronchus leading to a combination of atelectasis and retention of secretions. Also secondary infection beyond the obstruction may occur [51, 52]. In these circumstances, it can become difficult to differentiate the tumour from the surrounding lung consolidation.

During CT for the staging of lung cancer, additional small pulmonary nodules of soft tissue density are often found. In a study of 551 patients with lung cancer who had a staging CT and who were considered operable, 88 patients $(16 \%)$ were found to have small noncalcified pulmonary nodules. Adequate follow-up was possible in 25 patients who had a total of 36 nodules of which 25 nodules $(70 \%)$ were subsequently confirmed to be benign, 4 (11\%) were malignant and the nature of $7(19 \%)$ could not be determined [53]. The possibility of a second malignant nodule should be taken into account when staging lung cancer and strategy very much depends on site and location of the nodule and the cell type of the primary tumour.

\section{The $N$-factor}

Today, CT together with MRI give the best and most detailed information about presence, size, site, and morphological features of hilar and mediastinal lymph nodes. Although theoretically features such as nodal shape, density, and margins could help to differentiate benign from malignant lymph nodes, currently the only useful imaging sign for both CT and MRI is enlargement (fig. 2). Over the years, many studies have been performed in which lymph node size was used as a criterion for prediction of lymph node involvement with CT. The results of these studies are very disparate. Sensitivities between 41 and 95\% were found while specificity varied between 25 and $99 \%$ resulting in accuracy varying between 53 and $99 \%$. Positive predictive value (PPV) varied between 14 and $95 \%$, whereas negative predictive value varied between 79 and 96\% [26, 29, 54-62]. Method of nodal measurement together with size criterion used to define the presence of malignancy are the two most important reasons for this variation in results. Although most authors measured the short-axis diameter of the nodes as they appear on the axial images, especially in the early years some have measured the long axis. Currently, the consensus is to measure the short axis because this diameter is considered a more accurate predictor of nodal size [58, 63]. Size threshold above which a node is considered malignant is another variable. Independent of whether 


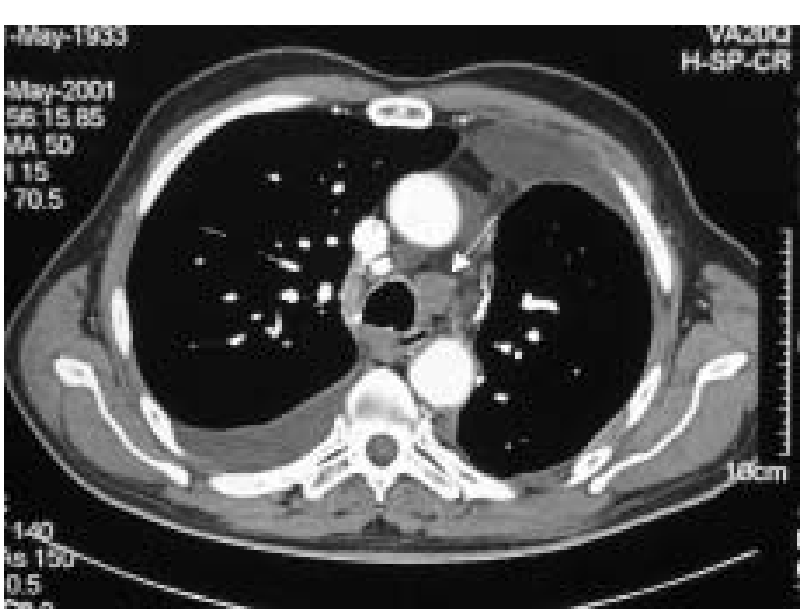

Fig. 2.-Lymph nodes in the mediastinum can be recognized easily and present as sharply defined intermediate density opacities (arrow). The current consensus considers nodes $>10 \mathrm{~mm}$ in shortaxis diameter as abnormal.

the short or long axis is measured it can be expected that a decrease in threshold value will increase sensitivity of CT and decrease its PPV. The current consensus considers nodes $>10 \mathrm{~mm}$ in short-axis diameter as abnormal.

The problem with using size as the only criterion for malignant nodal disease is that nodal enlargement may be due to multiple benign causes (e.g. reactive hyperplasia to the tumour or associated pneumonia or atelectasis, tuberculosis or other infections) and that normal-sized nodes may contain microscopic metastasis [64]. Results are worse in those populations where nonmalignant enlarged lymph nodes are seen more frequently because diseases such as histoplasmosis or fungal diseases are endemic [59]. Results are also worse in tumours such as adenocarcinomas or undifferentiated tumours, which are more aggressive and therefore more likely to reveal microscopic metastasis [60]. Patient selection also affects CT accuracy because it affects the prevalence of nodal disease. Some authors focused on clinical T1N0M0 tumours and concluded that routine CT scanning did not correctly stage their patient population [65]. However, others have found evidence for unresectable spread of disease in up to one-third of patients with T1N0M0 lung cancer and advocate routine preoperative CT in these patients [66]. Other variables such as differences in CT scanners, the scanning technique used and variation in the compulsiveness of surgical staging may also affect sensitivity and specificity of CT. Results are also different when radiological/surgical/pathological correlations are made on a node-by-node basis instead of on a patient-bypatient basis [61, 67]. Mcloud et al. [61] found that the right paratracheal group was the nodal station with the highest sensitivity as compared with other stations. The frequency of microscopic metastases to small nodes in patients without concurrent enlarged mediastinal nodes has been debated and is reported to occur in $8-60 \%$ of patients with mediastinal metastases [68, 69].

Many attempts have been made to improve the accuracy of CT. BuY et al. [70] increased the PPV to $95 \%$ by counting only lymph nodes which were at least $5 \mathrm{~mm}$ greater in diameter than nodes in regions not draining the tumour. Dillemans et al. [60] found a significant difference in PPV when comparing adenocarcinoma $(71 \%)$ and squamous cell carcinoma $(41 \%)$.

Currently, most authors agree that positive findings on CT (enlarged nodes) must be confirmed by a biopsy specimen and a pathological study. However, no consensus exists about what to do when a lung cancer patient has small mediastinal lymph nodes. Many investigators believe that normal CT findings (no nodes or small nodes) obviate preoperative lymph-node sampling and that these patients go directly to thoracotomy $[15,71]$. This approach is based on the fact that CT has a high negative predictive value in a lot of studies and on the findings that patients with microscopic metastasis to normalsized nodes have higher survival rates than patients with metastasis to enlarged nodes [71]. Others however believe that CT is not a good selector for mediastinoscopy or for other preoperative lymphnode sampling although it can guide the surgeon towards the enlarged lymph node [72]. It has been shown that the resectability rate in patients with unforeseen $\mathrm{N} 2$ disease (N2 detected at surgery) is higher when patients had a (false) negative cervical mediastinoscopy compared with patients who had no enlarged nodes on CT and did not undergo mediastinoscopy. Thus it may not be as crucial to detect microscopic spread of tumour preoperatively [73-75]. Generally, the false-negative rate of CT increases with higher T-status and is also higher in adenocarcinoma compared with squamous cell carcinoma [73]. For these reasons it was suggested by many investigators that only patients with squamous cell carcinoma staged as T1N0M0 by CT should go directly to thoracotomy without preoperative lymph node sampling. However, recent developments in therapy and the growing availability of PET scanners have changed this approach in some institutions. Very accurate knowledge of the $\mathrm{N}$-stage becomes more and more necessary since preoperative induction chemotherapy and radiation therapy are being used successfully to improve patient survival in some cases [76-80]. Many studies have shown that has a significantly higher sensitivity and specificity than CT in the detection of tumoural involvement of mediastinal lymph nodes [81-85]. However, PET will not be able to completely replace CT. The limited spatial resolution of this technique necessitates correlation with CT findings especially when accurate knowledge of the tumour-involved lymph nodes is necessary. It has been shown that the accuracy of PET can even be improved when the PET images are visually correlated with the CT images [86]. PET and CT images can also be fused. The hot spots obtained with PET will project on the CT images allowing correct identification and localization of the suspected lymph nodes. However, this fusion can only be successful if the CT scan is performed in exactly the same body position as the PET examination. Moreover, it has been shown that in most cases visual correlation is sufficient for adequate localization of the tumoural-invaded lymph 
nodes and that fusion should be reserved for those cases where this visual correlation fails [86].

\section{Evaluation of distant metastasis: the $M$ factor}

Several reports have studied the potential role of extrathoracic tumour spread in patients with newly diagnosed nonsmall cell lung cancer. SIDER et al. [87] demonstrated CT evidence of extrathoracic tumour spread in 24 of $95(25 \%)$ patients with newly diagnosed nonsmall cell lung cancer and N0 disease at thoracic CT. These included metastases to the brain, bone, liver, adrenals and soft tissue. A recent study by QuINT et al. [88] found 21\% overall prevalence of distant metastases in 348 patients with newly diagnosed nonsmall cell lung cancer. Brain, bone, liver and adrenal glands were the most common sites of disease in decreasing order.

Approximately $12 \%$ of patients with nonsmall cell carcinoma have clinically unsuspected hepatic metastases [89]. Ultrasound (US) and CT appear to have similar accuracy. CT, of course, more readily demonstrates regions that are difficult to assess with US and can distinguish more reliably between metastatic deposits and benign lesions [90]. In addition because it allows contrast dynamics in the liver to be optimized and permits overlapping reconstruction intervals, spiral CT has increased the ability of CT to detect hepatic metastases. However the need for optimal contrast in the liver means that it is technically difficult to combine this with a good contrastenhanced chest CT (i.e. extending the chest CT into the upper abdomen). In addition, QuINT et al. [88] found that isolated liver metastases are uncommon and concluded that the incremental yield of abdominal CT over chest CT was quite small making an abdominal CT not generally necessary.

SALVATIERRA et al. [89] found a 7.5\% prevalence of adrenal metastases in 146 patients with lung cancer. A CT examination used for staging bronchogenic carcinoma should include the upper abdomen. Indeed, examination of the adrenal glands can be done easily at the time of the CT examination of the chest. However, two-thirds of the adrenal masses identified by CT in patients with lung carcinoma are adenomas [91]. Most incidental nonhyperfunctioning adenomas are $<3 \mathrm{~cm}$ in diameter and of uniform low attenuation $(<10$ Hounsfield units) because of their fat content (fig. 3). These density measurements should be performed on unenhanced CT examinations because intravenous contrast can increase the density of the adrenal nodule. In lesions not meeting these criteria dedicated noncontrast CT, delayed enhanced CT or even, needle aspiration biopsy of the adrenal nodule may be necessary [92-94]. Also MRI may be helpful in the distinction of adrenal metastases from adenoma when chemical shift imaging is used $[95,96]$.

$\mathrm{CT}$ is the standard examination to depict brain metastases. However MRI has a higher sensitivity and detects significantly smaller brain metastases [97]. Brain CT is usually only performed when symptoms are present or in aggressive tumours. The chance of brain metastasis even in patients with normal

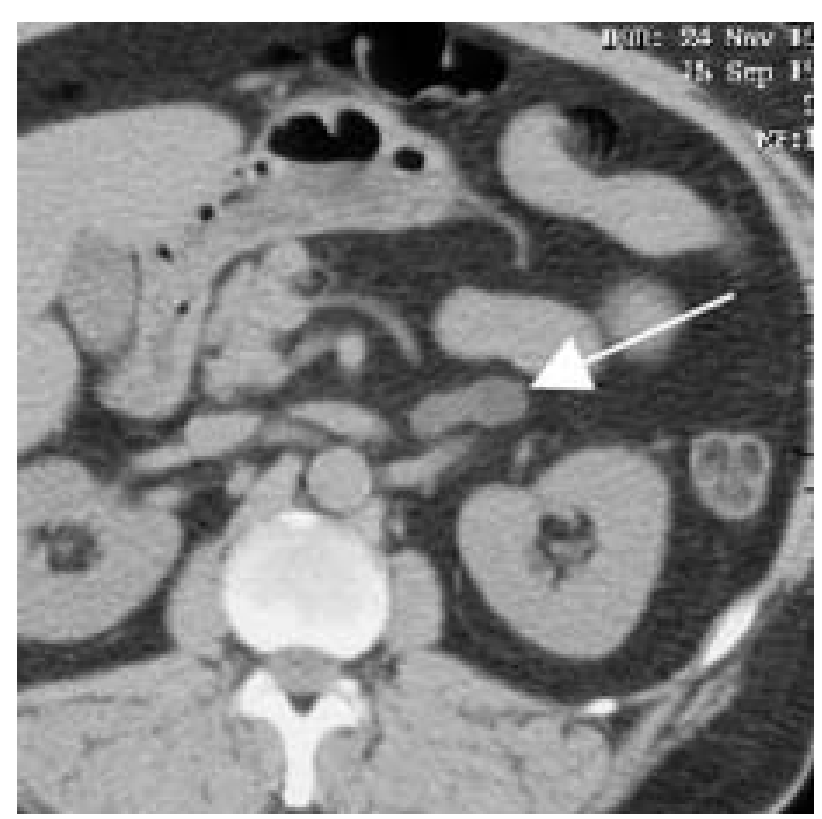

Fig. 3.-Incidental adenoma in the left adrenal. A mass with a diameter $<3 \mathrm{~cm}$ and a uniform low attenuation.

neurological examination increases when the tumour is more aggressive [98].

\section{Conclusions}

Despite its well-known limitations, CT remains the routine imaging procedure for determining resectability and assessing intra- and extrathoracic spread of lung cancer. This technique provides the most detailed imaging information of the tumour and its extent. Staging lung cancer is, of course, a multidisciplinary process, which also utilizes other procedures such as bronchoscopy and biopsy. It is not surprising that the role of CT in this process is continuously changing. There is not only a continuous technical improvement in the CT technique itself but also a continuous improvement of old, and a development of new, diagnostic and therapeutic procedures.

State of the art spiral and multi-detector CT scanners are able to present very detailed $2 \mathrm{D}$ or even 3D images of the tumour and its extent in the surrounding tissues. These scanners depict with greater confidence invasion of tumour in the fissure, the chest wall or the mediastinum. In addition they may show definitively that the tumour is too extensive for resective surgery. However, despite this improved image quality, there are still a lot of cases where CT may leave this in doubt. MRI may than be used as a problem solving modality, but again this may not always be able to solve the problem.

$\mathrm{CT}$ has a poor specificity in determining nodal involvement and the newer CT systems have not changed this. A biopsy confirmation of neoplastic nodal involvement is necessary before a patient is denied surgery. The role of CT is limited but important. It offers the surgeon a road-map of the lymph nodes in the hilum and the mediastinum, and 
guides him towards the nodes that need a biopsy. Combining CT and PET will certainly improve nodal staging of the mediastinum and will reduce the number of unnecessary interventional procedures.

Computed tomography has an important role in staging for distant metastases. Faster scanners allow computed tomography examination of the chest and of the adrenals to be combined in one examination. That is why a chest computed tomography should always include the upper abdomen. Including staging of the liver in this procedure is technically difficult because optimal contrast enhancement of the liver is necessary in order to depict metastatic disease, which is difficult to obtain together with a good contrastenhanced chest computed tomography. Although magnetic resonance imaging (MRI) is more sensitive, computed tomography is, because it is more widely available, the technique of choice to depict brain metastasis.

\section{References}

1. Evens RG. New frontier for radiology: computed tomography. 40th Annual Preston M. Hickey Memorial Lecture. Am J Roentgenol 1976; 126: 1117-1129.

2. Maravilla KR, Pastel MS. Technical aspects of CT scanning. Comput Tomogr 1978; 2: 137-144.

3. TerPogossian MM. Basic principles of computed axial tomography. Semin Nucl Med 1977; 7: 109-127.

4. Kalender WA, Seissler W, Vock P. Single-breath-hold spiral volumetric CT by continuous patient translation and scanner rotation. Radiology 1989; 173: 414.

5. Kalender WA, Polacin A, Süss C. A comparison of conventional and spiral CT: an experimental study on detection of spherical lesions. J Comput Assist Tomogr 1994; 18: 167-176.

6. Schoepf UJ, Becker C, Bruning R, et al. Computed tomography of the abdomen with multidetector-array CT. Radiologe 1999; 39: 652-661.

7. Berland LL, Smith JK. Multidetector array CT: one again, technology creates new opportunities. Radiology 1998; 209: 327-329.

8. Uffmann M, Prokop M. Multislice CT of the lung. Technique and clinical applications. Radiologe 2001; 41: 240-247.

9. Meziane MA, Hruban RH, Zerhouni EA, et al. High resolution $\mathrm{CT}$ of the lung parenchyma with pathologic correlation. Radiographics 1988; 8: 27-54.

10. Murata K, Khan A, Rojas KA, Herman PG. Optimization of computed tomography technique to demonstrate the fine structure of the lung. Invest Radiol 1988; 23: 170-175.

11. Schaefer-Prokop C, Prokop M. New imaging techniques in the treatment guidelines for lung cancer. Eur Respir J 2002; 19: Suppl. 35, 71s-83s.

12. Primack SL, Lee KS, Logan PM, Miller RR, Müller NL. Bronchogenic carcinoma: utility of CT in the evaluation of patients with suspected lesions. Radiology 1994; 193: 795-800.

13. Lahde S, Paivansalo M, Rainio P. CT for predicting the resectability of lung cancer: a prospective study. Acta Radiol 1991; 32: 449-454.

14. Lewis JW, Madrazo BL, Gross SC. The value of radiographic and computed tomography in the staging of lung carcinoma. Ann Thorac Surg 1982; 34: 553558.

15. Lewis JW, Pearlberg JL, Beute GH, et al. Can computed tomography of the chest stage lung cancer? Yes and no. Ann Thorac Surg 1990; 49: 591596.

16. Kesler KA, Conces DJ, Heimansohn DA, Mathur P. Assessing the feasibility of bronchoplastic surgery with magnetic resonance imaging. Ann Thorac Surg 1991; 52: 145-147.

17. Mayr B, Lenhard M, Fink U, Heywang-Köbrunner $\mathrm{SH}$, Sunder-Plasman L, Permanetter W. Preoperative evaluation of bronchogenic carcinoma: value of MR in T- and N-staging. Eur J Radiol 1992; 14: 245-251.

18. Herman SJ, Winton TL, Weisbrod GL, Tower MJ, Mentzer SJ. Mediastinal invasion by bronchogenic carcinoma: CT signs. Radiology 1994; 190: 841-846.

19. Glazer HS, Kaiser LR, Anderson DJ, et al. Indeterminate mediastinal invasion in bronchogenic carcinoma: CT evaluation. Radiology 1989; 173: 37-42.

20. McLoud TC. CT of bronchogenic carcinoma: indeterminate mediastinal invasion. Radiology 1989; 173 : $15-16$.

21. Izbicki J, Thetter O, Karg O. Accuracy of computed tomographic scan and surgical assessment for staging of bronchial carcinoma. J Thorac Cardiovasc Surg 1992; 104: 413-420.

22. Allen MS, Mathisen DJ, Grillo HC, Wain JC, Moncure AC, Hilgenberg AD. Bronchogenic carcinoma with chest wall invasion. Ann Thorac Surg 1991; 51: 948-951.

23. McCaughan BC, Martini N, Bains MS, McCormack PM. Chest wall invasion in carcinoma of the lung: therapeutic and prognostic implications. $J$ Thorac Cardiovasc Surg 1985; 89: 836-841.

24. Pearlberg JL, Sandler MA, Beute GH, Lewis JW, Madrazo BL. Limitations of CT in evaluation of neosplasms involving chest wall. $J$ Comput Assist Tomogr 1987; 11: 290-293.

25. Pennes DR, Glazer GM, Wimbish KJ, Gross BH, Long RW, Orringer MB. Chest wall invasion by lung cancer: limitations of CT evaluation. Am J Roentgenol 1985; 144: 507-511.

26. Webb WR, Gatsonis C, Zerhouni EA, et al. CT and MR imaging in staging non-small cell bronchogenic carcinoma: report of the radiologic diagnostic oncology group. Radiology 1991; 148: 705-713.

27. Epstein DM, Stephenson LW, Gefter WB, van der Voorde F, Aronchik JM, Miller WT. Value of CT in the preoperative assessment of lung cancer: a survey of thoracic surgeons. Radiology 1986; 161: 423-427.

28. Grenier P, Dubray B, Carette MF, Frija G, Musset D, Chastang C. Preoperative thoracic staging of lung cancer: CT and MR evaluation. Diagn Intervent Radiol 1989; 1: 23-28.

29. Gdeedo A, VanSchil P, Corthouts B, VanMieghem F, VanMeerbeeck J, VanMarck E. Comparison of imaging TNM ((i)TNM) and pathological TNM ((p)TNM) in staging of bronchogenic carcinoma. Eur J Cardiothorac Surg 1997; 12: 224-227.

30. Ratto GB, Piacenza G, Frola C, et al. Chest wall involvement by lung cancer: computed tomographic detection and results of operation. Ann Thorac Surg 1991; 51: 182-188.

31. Scott IR, Muller NL, Miller RR, Evans KG, Nelems B. Resectable Stage III lung cancer: CT, surgical and pathologic correlation. Radiology 1988; 166: 75-79. 
32. Shirakawa T, Fukuda K, Miyamoto Y, Tanabe H, Tada S. Parietal pleural invasion of lung masses: evaluation with CT performed during deep inspiration and expiration. Radiology 1994; 192: 809-811.

33. Watanabe A, Shimokata K, Saka H, Nomura F, Sakai S. Chest CT combined with artificial pneumothorax: value in determining origin and extent of tumor. $A J R$ 1991; 156: 707-710.

34. Yokoi K, Mori K, Miyazawa N, Saito Y, Okuyama A, Sasagawa M. Tumor invasion of the chest wall and mediastinum in lung cancer: evaluation with pneumothorax CT. Radiology 1991; 181: 147-152.

35. Uhrmeister P, Allmann KH, Wertzel $\mathrm{H}$, et al. Chest wall infiltration by lung cancer: value of thin-sectional CT with different reconstruction algorithms. Eur Radiol 1999; 9: 1304-1309.

36. Kuriyama K, Hosomi N, Sawai Y, et al. Threedimensional imaging of focal lung disease using spiral volumetric CT. Jpn J Clin Radiol 1994; 39: 9-13.

37. Kuriyama K, Tateishi R, Kumatani $\mathrm{T}$, et al. Pleural invasion of peripheral bronchogenic carcinoma: assessment with three-dimensional helical CT. Radiology 1994; 191: 365-369.

38. LoCicero J, Costello R, Campos CT, et al. Spiral CT with multiplanar and three-dimensional reconstructions accurately predicts tracheobronchial pathology. Ann Thorac Surg 1996; 62: 811-817.

39. Lorensen WE, Jolesz FA, Kikinis R. The exploration of cross-sectional data with a virtual endoscope. In: Morgan K, Satava RM, Sieburg HB, Mattheus R, Christensen JP, eds. Interactive Technology and the New Paradigm for Healthcare. Ohmsha, IOS Press, 1995; pp. 221-230.

40. Kim Y, Soo Lee K, Yoon JH, et al. Tuberculosis of the trachea and main bronchi: CT findings in 17 patients. AJR 1997; 168: 1051-1056.

41. Remy J, Remy-Jardin M, Artaud D, Fribourg M. Multiplanar and three-dimensional reconstruction techniques in CT: impact on chest diseases. Eur Radiol 1998; 8: 335-351.

42. Hawkes DJ, Ruff CF, Studholme C, Edwards PJ, Wong WL, Padhani A. Three-dimensional multimodal imaging in image-guided interventions. Sem Intervent Radiol 1995; 12: 63-74.

43. Thompson BH, Stanford W. MR imaging of pulmonary and mediastinal malignancies. Magn Reson Imaging Clin N Am 2000; 8: 729-739.

44. Musset D, Grenier P, Carette MF, et al. Primary lung cancer staging: prospective comparative study of MR imaging with CT. Radiology 1986; 160: 607-611.

45. Padovani B, Mouroux J, Seksik L, et al. Chest wall invasion by bronchogenic carcinoma: evaluation with MR imaging. Radiology 1993; 187: 33-38.

46. Castagno A, Shuman W. MR imaging in clinically suspected brachial plexus tumor. AJR 1987; 149: 1219-1222.

47. Takasugi J, Rapoport S, Shaw C. Superior sulcus tumors: the role of imaging. $J$ Thorac Imag 1989; 4: $41-48$.

48. Rapoport S, Blair D, McCarthy S, Desser T, Hammers L, Sostman H. Brachial plexus: correlation of MR imaging with CT and pathologic findings. Radiology 1988; 167: 161-165.

49. Freundlich I, Chasen M, Datla G. Magnetic resonance imaging of pulmonary apical tumors. $J$ Thorac Imag 1996; 11: 210-222.

50. Deschildre F, Petyt L, Rémy-Jardin M, Rémy J,
Wannebroucq J. Evaluation de la TDM par balayage spirale volumique (BSV) vs IRM dans le bilan d'extension pariétal des masses thoraciques. Rev Im Med 1994; 6: 188.

51. Woodring JH. Determining the cause of pulmonary atelectasis: a comparison of plain radiography and CT. Am J Roentgenol 1988; 150: 757-763.

52. Rohlfing BM, White EA, Webb WR, Goodman PC. Hilar and mediastinal adenopathy caused by bacterial abscess of the lung. Radiology 1978; 128: 289-293.

53. Keogan MT, Tung KT, Kaplan DK, Goldstraw PJ, Hansell DM. The significance of pulmonary nodules detected on CT staging for lung cancer. Clin Radiol 1993; 48: 94-96.

54. Grover FL. The role of CT and MRI in staging of the mediastinum. Chest 1994; 106: 391S-396S.

55. Quint LE, Francis IR, Wahl RL, Gross BH, Glazer GM. Preoperative staging of non-small-cell carcinoma of the lung: imaging methods. AJR 1995; 164: 13491359.

56. Webb WR, Golden JA. Imaging strategies in the staging of lung cancer. Clin Chest Med 1991; 12: 133150 .

57. Armstrong P, Vincent JM. Staging non-small cell lung cancer. Clin Radiol 1993; 48: 1-10.

58. Glazer GM, Gross BH, Quint LE, Francis IR, Bookstein FL, Orringer MB. Normal mediastinal lymph nodes: number and size according to American Thoracic Society mapping. AJR 1985; 144: 261-265.

59. Ikezoe J, Kadowaki K, Morimoto S. Mediastinal lymph node metastases from non-small-cell bronchogenic carcinoma: re-evaluation with CT. J Comput Assist Tomogr 1990; 14: 340-344.

60. Dillemans B, Deneffe G, Verschakelen J, Decramer M. Value of computed tomography and mediastinoscopy in preoperative evaluation of mediastinal nodes in non-small cell lung cancer. Eur J Cardiothorac Surg 1994; 8: 37-42.

61. McLoud TC, Bourgouin PM, Greenberg RW, et al. Bronchogenic carcinoma: analysis of staging in the mediastinum with $\mathrm{CT}$ by correlative lymph node mapping and sampling. Radiology 1992; 182: 319-323.

62. Dales R, Stark R, Raman S. Computed tomography to stage lung cancer. Am Rev Respir Dis 1990; 144: 1096-1101.

63. Quint L, Glazer G, Orringer M, Francis I, Bookstein F. Mediastinal lymph node detection and sizing azt CT and autopsy. AJR 1986; 147: 469-472.

64. Daly BJ, Faling L, Pugath R. Computed tomography. An effective technique for mediastinal staging in lung cancer. J Thorac Cardiovasc Surg 1984; 88: 486-494.

65. Becker GL, Whitlock WL, Schaefer PS, Tenholder MF. The impact of thoracic computed tomography in clinically staged T1 N0, MO chest lesions. Arch Intern Med 1990; 150: 557-559.

66. Parker LA, Mauro MA, Delany DJ. Evaluation of T1N0M0 lung cancer with CT. J Comput Assist Tomogr 1991; 15: 943-947.

67. Seely JM, Mayo JR, Miller RR, Müller NL. T1 lung cancer: prevalence of mediastinal nodal metastases and diagnostic accuracy of CT. Radiology 1993; 186: $129-132$.

68. Gross B, Glazer G, Orringer M, Spizarny D, Flint A. Bronchogenic carcinoma metastatic to normal-sized lymph nodes: frequency and significance. Radiology 1988; 166: 71-74.

69. Arita T, Matsumoto T, Kuramitsu T, Kawamura N, 
Sugi K, Esato K. Is it possible to differentiate malignant mediastinal nodes from benign nodes by size? Reevaluation by CT, transesophageal echocardiography, and nodal specimen. Chest 1996; 110: 1004-1008.

70. Buy JN, Ghossain MA, Poirson F, et al. Computed tomography of mediastinal lymph nodes in nonsmallcell lung cancer. A new approach based on the lymphatic pathway of tumor spread. $J$ Comput Assist Tomogr 1988; 12: 545-552.

71. Daly BD, Mueller JD, Faling LJ, et al. N2 lung cancer: outcome in patients with false-negative computed tomographics scans of the chest. J Thorac Cardiovasc Surg 1993; 105: 904-911.

72. Harrow EM, Abi-Saleh W, Blum J, et al. The utility of transbronchial needle aspiration in the staging of bronchogenic carcinoma. Am J Respir Crit Care Med 2000; 161: 601-607.

73. DeLeyn P, Schoonooghe P, Deneffe G, et al. Surgery for non-small cell lung cancer with unsuspected metastasis to ipsilateral mediastinal or subcarinal nodes (N2 disease). Eur J Cardiothorac Surg 1996; 10: 649-655.

74. Pearson F, DeLarue N, Ilves R, Todd T, Cooper J. Significance of positive superior mediastinal nodes identified at mediastinoscopy in patients with resectable cancer of the lung. J Thorac Cardiovasc Surg 1982; 83: 1-11.

75. Cybulsky I, Lanza L, Ryan M, Putman J, McMurtrey M, Roth J. Prognostic significance of computed tomography in resected N2 lung cancer. Ann Thorac Surg 1992; 54: 533-537.

76. Martini N, Kris MG, Flehinger BJ, et al. Preoperative chemotherapy for stage IIIa (N2) lung cancer: the Sloan-Kettering experience with 136 patients. Ann Thorac Surg 1993; 55: 1365-1374.

77. Roth JA, Fossella F, Komaki R, et al. A randomized trial comparing perioperative chemotherapy and surgery with surgery alone in resectable stage IIIA non-small cell lung cancer. J Natl Cancer Inst 1994 86: 673-680.

78. Taylor SI, Trybula M, Bonomi P. Simultaneous cisplatin fluorouracil infusion and radiation followed by surgical resection in regionally localized stage III, non-small cell lung cancer. Ann Thorac Surg 1987; 43: 87-91.

79. Rosell R, Gomez-Codina J, Camps C, et al. A randomized trial comparing chemotherapy plus surgery with surgery alone in patients with non-small-cell lung cancer. N Engl J Med 1994; 330: 153-158.

80. Vansteenkiste J, De Leyn P, Deneffe G, Menten J, Lerut T, Demedts M. Present status of induction treatment in stage IIIA-N2 non-small cell lung cancer: a review. Eur J Cardiothorac Surg 1998; 13: 1-12.

81. Vansteenkiste JF, Stroobants SG, De Leyn PR, et al. Mediastinal lymph node staging with FDG-PET scan in patients with potentially operable non-small cell lung cancer: a prospective analysis of 50 cases. Chest 1997; 112: 1480-1486.

82. Vansteenkiste JF, Stroobants SG, De Leyn PR, et al. Lymph node staging in non-small-cell lung cancer with FDG-PET scan: a prospective study on 690 lymph node stations from 68 patients. J Clin Oncol 1998; 16: 2142-2149.
83. Kernstine KH, Stanford W, Mullan BF, et al. PET, $\mathrm{CT}$, and MRI with Combidex for mediastinal staging in non-small cell lung carcinoma. Ann Thorac Surg 1999; 68: 1022-1028.

84. Steinert HC, Hauser M, Allemann F, et al. Non-small cell lung cancer: nodal staging with FDG PET versus CT with correlative lymph node mapping and sampling. Radiology 1997; 202: 441-446.

85. Wahl RL, Quint LE, Greenough RL, Meyer CR, White RI, Orringer MB. Staging of mediastinal nonsmall cell lung cancer with FDG PET, CT, and fusion images: preliminary prospective evaluation. Radiology 1994; 191: 371-377.

86. Vansteenkiste JF, Stroobants SG, Dupont PJ, et al. FDG-PET scan in potentially operable non-small cell lung cancer: do anatometabolic PET-CT fusion images improve the localisation of regional lymph node metastases? Eur J Nucl Med 1998; 25: 1495-1501.

87. Sider L, Horejs D. Frequency of extrathoracic metastases from bronchogenic carcinoma in patients with normal-sized hilar and mediastinal lymph nodes on CT. AJR 1988; 151: 893-895.

88. Quint LE, Tummala S, Brisson LJ, et al. Distribution of distant metastases from newly diagnosed non-small cell lung cancer. Ann Thorac Surg 1996; 62: 246-250.

89. Salvatierra A, Baamonde C, Llamas JM, Cruz F, Lopez-Pujol J. Extrathoracic staging of bronchogenic carcinoma. Chest 1990; 97: 1052-1058.

90. Yeh HC, Rabinowitz JG. Ultrasonography and computed tomography of the liver. Radiol Clin North Am 1980; 18: 321-338.

91. Oliver TW, Bernardino ME, Miller JI, Mansour K, Greene D, Davis WA. Isolated adrenal masses in nonsmall cell bronchogenic carcinoma. Radiology 1984; 153: 217-218.

92. Korobkin M, Brodeur FJ, Yutzy GG, et al. Differentiation of adrenal adenomas from nonadenomas using CT attenuation values. AJR 1996; 166: 531-536.

93. Korobkin M, Brodeur F, Francis I, Quint L, Dunnick N, Goodsitt M. Delayed enhanced CT for differentiation of benign from malignant adrenal masses. Radiology 1996; 200: 737-742.

94. Korobkin M, Brodeur F, Francis I, Quint L, Dunnick N. CT time-attenuation washout curves of adrenal adenomas and non-adenomas. AJR 1998; 170: 747752.

95. Schwartz LH, Panicek DM, Koutcher JA, et al. Adrenal masses in patients with malignancy: prospective comparison of echoplanar, fast spin-echo, and chemical shift MR imaging. Radiology 1995; 197: 421425.

96. Korobkin M, Lombardi TJ, Aisen AM, et al. Characterization of adrenal masses with chemical shift and gadolinium-enhanced MR imaging. Radiology 1995; 197: 411-418.

97. Yokoi K, Kamiya N, Matsuguma H, et al. Detection of brain metastasis in potentially operable non-small cell lung cancer: a comparison of CT and MRI. Chest 1999; 115: 714-719.

98. Tarver RD, Richmond BD, Klatte EC. Cerebral metastases from lung carcinoma: neurological and CT correlation. Work in progress. Radiology 1984; 153: 689-692. 